\title{
THE INFLUENCE OF EPIDURAL ANAESTHESIA ON CARDIAC EXCITABILITY IN PROFOUND HYPOTHERMIA
}

\author{
A Galindo, M D , aNd J $H$ Sprouse, $M$ d $\nmid$
}

In NON-ANAESTHETIZED PATIENTS who are subjected to a lethal level of hypothermia, the cause of death is believed to be related to autonomic reflexes which might induce ventricular fibrillation It has been shown that surgical sympathectomy, ${ }^{2}$ sympatholisis with drugs, ${ }^{3}$ and deep general anaesthesia ${ }^{4}$ decreased the occurrence of hypothermic ventricular fibrillation In this laboratory we demonstrated that with total epidural anaesthesia, animals can be cooled to lower temperatures before their hearts fibrillate ${ }^{4-8}$

The purpose of this investigation was to ascertain the relationship between the observed protection of sympathetic block and ventricular excitability during hypothermia

\section{METHOD}

Twenty mongrel dogs were used in this series of experiments "Thiopentone $20 \mathrm{mg} / \mathrm{kg}$ was administered intravenously for induction After endotracheal intubation, the animals were ventilated artificially with 100 per cent oxygen using a Bird respirator (Mark 8) Succinylcholine $10 \mathrm{mg}$ was administered intravenously every $20-30$ minutes Hypothermia was obtained by extracorporeal blood cooling using a technique described in detall elsewhere ${ }^{6}$ In brief, the femoral artery and veln were cannulated, blood was taken from the femoral artery $(10 \mathrm{c} \mathrm{c} / \mathrm{kg} /$ munute $)$, cooled to $20^{\circ}-25^{\circ} \mathrm{C}$, and returned to the femoral vein This shunt was sustaned until the oesophageal temperature reached $27^{\circ}-30^{\circ} \mathrm{C}$ At this temperature, the direction of the shunt was reversed, the blood flow was increased to 20 to $30 \mathrm{cc} / \mathrm{kg} /$ mmute, and maintained unt1l an oesophageal temperature of $10^{\circ} \mathrm{C}$ was achieved The extracorporeal system was primed with blood obtanned from donor dogs Oxygen 100 per cent was used in the oxygenator Artıficial respuration was discontunued below $25^{\circ} \mathrm{C}$ of oesophageal temperature Lead 2 of the $\mathbb{E} C \mathbb{G}$, the fronto-occipital lead of the $\mathbb{E} \mathbb{E}$, the oesophageal temperature, the arterial blood pressure, and the venous blood pressure were recorded with a Sanborn 150 polygraph Statham transducers were used for pressure determmations $\mathbb{F}$ ive millilitres of arterial blood were withdrawn at normal temperature, and at $35^{\circ}$ and $5^{\circ}$ untervals thereafter for $\mathrm{pHI}$ and $p \mathrm{CO}_{2}$ determinations The experiment was discontinued when ventriculas fibrillation occurred or the oesophageal temperature reached $10^{\circ} \mathrm{C}$

\footnotetext{
* Section on Neuroanesthesılogy, Surgical Neurology, National Institute of Neurological Diseases and Blindness, Natronal Institutes of Health.

Present address McGill Unversity, Montreal Neurologic al Institute, Montreal, Canada

†Anesthesiology Department, Clinical Center, National Institutes of Health

Present address University of Kentucky, Department of Anesthesiology, Lexingilon, Ky
} 
To determine the excitability of the ventricle, the chest was opened and a bipolar electrode was placed in the left ventricular wall An electrical stimulus of 2-msec duration and variable current was applied to the ventricular myocardium to obtain a premature ventricular contraction The strength of the current varied according to its temporal relationship with the preceding $R$ wave and the excitability of the left ventricle, this technique is described elsewhere. ${ }^{5}$

For control determinations, hypothermia was induced in 15 succinylcholineparalysed and lightly anaesthetized animals Determinations of cardiac excitability were made throughout the cooling period

In five animals, epıdural anaesthesia with lidocaine $5 \mathrm{mg} / \mathrm{kg}$ of 1 per cent solution was administered through a catheter placed in the epidural space and similas determinations of cardiac excitability were performed Hypothermia was induced as in the control gloup

\section{RESULTS}

The ventricular diastolic thieshold (minimal electrical current needed to produce an extrasystole during the electrical diastole) of the 15 control animals had wide oscllations It was higher than control at temperatures above $25^{\circ} \mathrm{C}$ It decreased sharply below this temperature in some experiments In contrast, this threshold was stable in the epidual anmals, with a small increase under $25^{\circ} \mathrm{C}$ (Fig 1, Table I)

In all control anmals, ventricular fibrillation was started when testng with

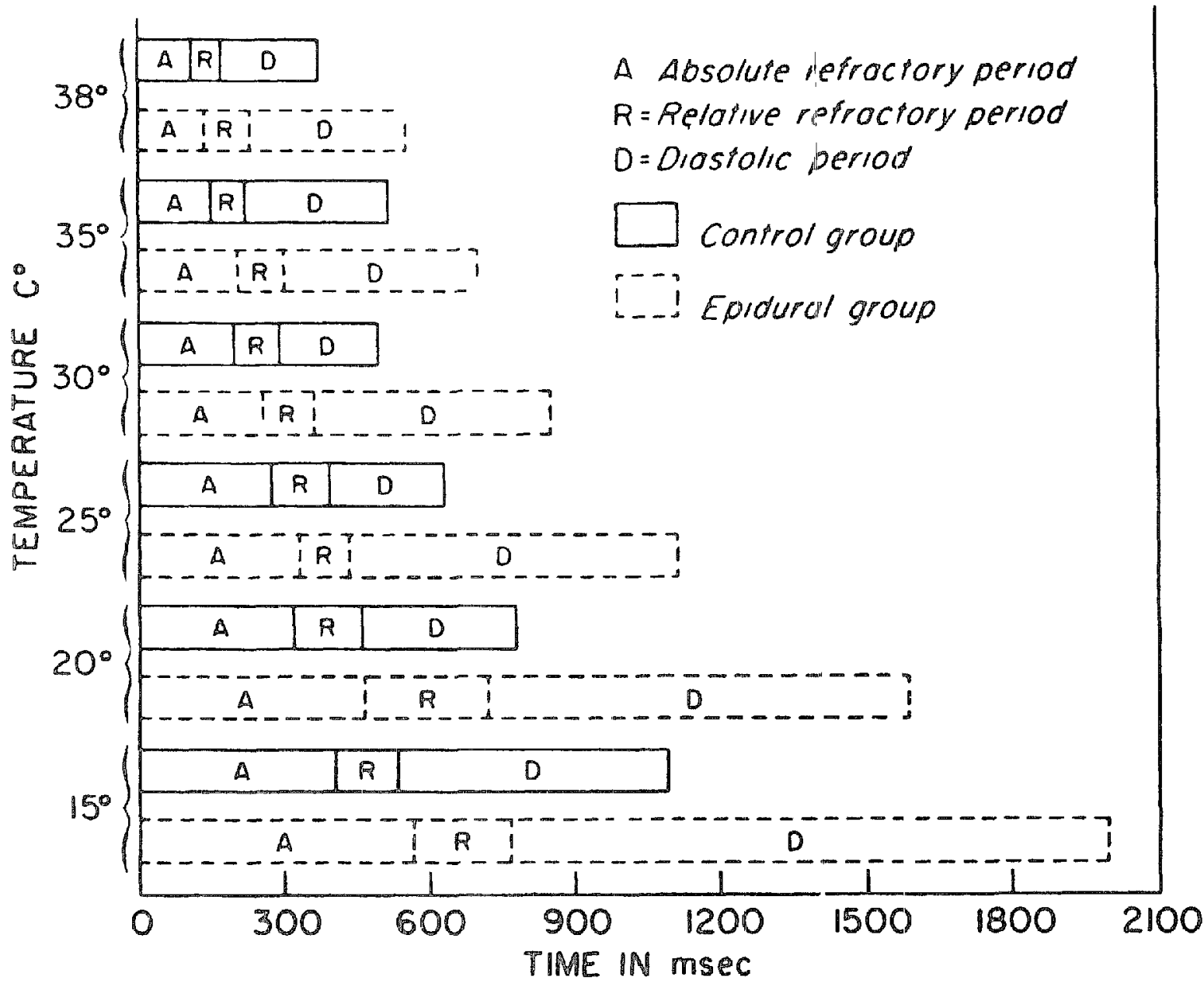

FIGURE I Relative and absolute changes of the various strength-interval curve periods as a function of temperature 
TABLE II

\begin{tabular}{|c|c|c|c|c|c|c|c|c|}
\hline & \multicolumn{2}{|c|}{ T R P (msec) } & \multicolumn{2}{|c|}{ T R P $(\%)$} & \multicolumn{2}{|c|}{ VDT (mamp) } & \multicolumn{2}{|c|}{$\mathrm{HR}(\mathrm{B} / \mathrm{m} \ln )$} \\
\hline & C & $\mathrm{E}$ & $\mathrm{C}$ & $\mathrm{E}$ & $\mathrm{C}$ & $\mathrm{E}$ & $\mathrm{C}$ & $\mathrm{E}$ \\
\hline Control & 170 & 200 & 459 & 50 & 010 & $\begin{array}{ll}0 & 125\end{array}$ & 162 & 150 \\
\hline Epidural & - & 204 & - & $371^{0}$ & - & 0124 & & $109^{+}$ \\
\hline $35^{\circ} \mathrm{C}$ & $222^{+}$ & $298_{0}^{+}$ & 493 & $420^{\circ}$ & 013 & $0116^{0}$ & $133^{+}$ & $85_{0}^{+}$ \\
\hline $30^{\circ} \mathrm{C}$ & $288^{+}$ & $356^{+}$ & 576 & $4 \| 4^{0}$ & 014 & $0120^{\circ}$ & $119^{+}$ & $70_{0}^{+}$ \\
\hline $25^{\circ} \mathrm{C}$ & $396^{+}$ & $442^{+}$ & 609 & $398^{\circ}$ & 015 & $0136^{\circ}$ & $93^{+}$ & $54{ }_{0}^{+}$ \\
\hline $20^{\circ} \mathrm{C}$ & $471^{+}$ & $720^{+}$ & 620 & $468^{0}$ & 013 & $0132^{0}$ & $79^{+}$ & $39_{\circ}^{+}$ \\
\hline $15^{\circ} \mathrm{C}$ & $533^{+}$ & $783^{+}$ & 472 & $392^{0}$ & 014 & $016^{0}$ & $53^{+}$ & $30_{0}^{+}$ \\
\hline
\end{tabular}

T R P (msec) - total refractory period in milliseconds

T R P $(\%)$-total refractory period as a percentage of the heart cycle

V D T (mamp)-ventricular diastolic threshold in millamperes

H R (B/mın) -heart sate, beats per minute

$\mathrm{C}=$ control, $\mathrm{E}=$ experimental

o $P<0$ 02, experimental group against control group

$+P<002$, for the same group

diastolic threshold levels of current applied during the last 20 msec of the relative refractory period (vulnerable pelıd ${ }^{7}$ ) It occurred at a higher temperature $\left(24^{\circ} \mathrm{C}\right.$ to $\left.15^{\circ} \mathrm{C}\right)$ in those animals with lower ventricular drastolic threshold.

All dogs in the control group suffered venticular fibrillation at temperatures between $24^{\circ} \mathrm{C}$ and $11^{\circ} \mathrm{C}$ In five animals of the epidural group only two fibrillated $\left(13^{\circ} \mathrm{C}\right.$ and $11^{\circ} \mathrm{C}$ )

The epidural group had a steady decrease in heart rate between $35^{\circ} \mathrm{C}$ and $20^{\circ} \mathrm{C}$ ( 3 beats per degree) The deciease was sharper ( 6 beats per degree) for the first two degrees $\left(37^{\circ}\right.$ to $35^{\circ} \mathrm{C}$ ) and slower for the last five $\left(20^{\circ}\right.$ to $15^{\circ} \mathrm{C}$ ) The control group had marked heart-rate changes of no definite pattern ( $F_{1}$ g 2, Table I) This rate was higher than in the epiclural gioup at any given temperature The mean blood pressure had a slow hypothermic drop in the control group, but was rapidly decreased in the epidural group

The length of the QRS, at any given temperature, showed no difference between the control and the epidural group

Cooling the epidural group had no effect on the percentage of the heart cycle components absolute and relative refractory periods, and diastolic period They were greatly modified in the control group ( $\mathbb{F} 1 \mathrm{~g} 1)$

\section{Discussion}

The protection offered by epidural anaesthesia against hypothermic ventricular fibrillation was partial, and it was not related to the ventricular diastolic threshold changes despite its stability in the epidural anaesthesia group when compared to the controls ( Table $\mathbb{I}$ )

Goldberg reported the occurrence of hypothermic arrhythmias at higher temperatures with sympathetic block Israel, ${ }^{,}$using total spinal anaesthesia, found no protection against cardiac arrhythmias induced by the administration of epinephrine In the former study, a veno-venous shunt of extracorporeal cooling was used without circulatory support, while in the latter, the administration of epinephrme as a test of cardiac excitability has questronable meaning 


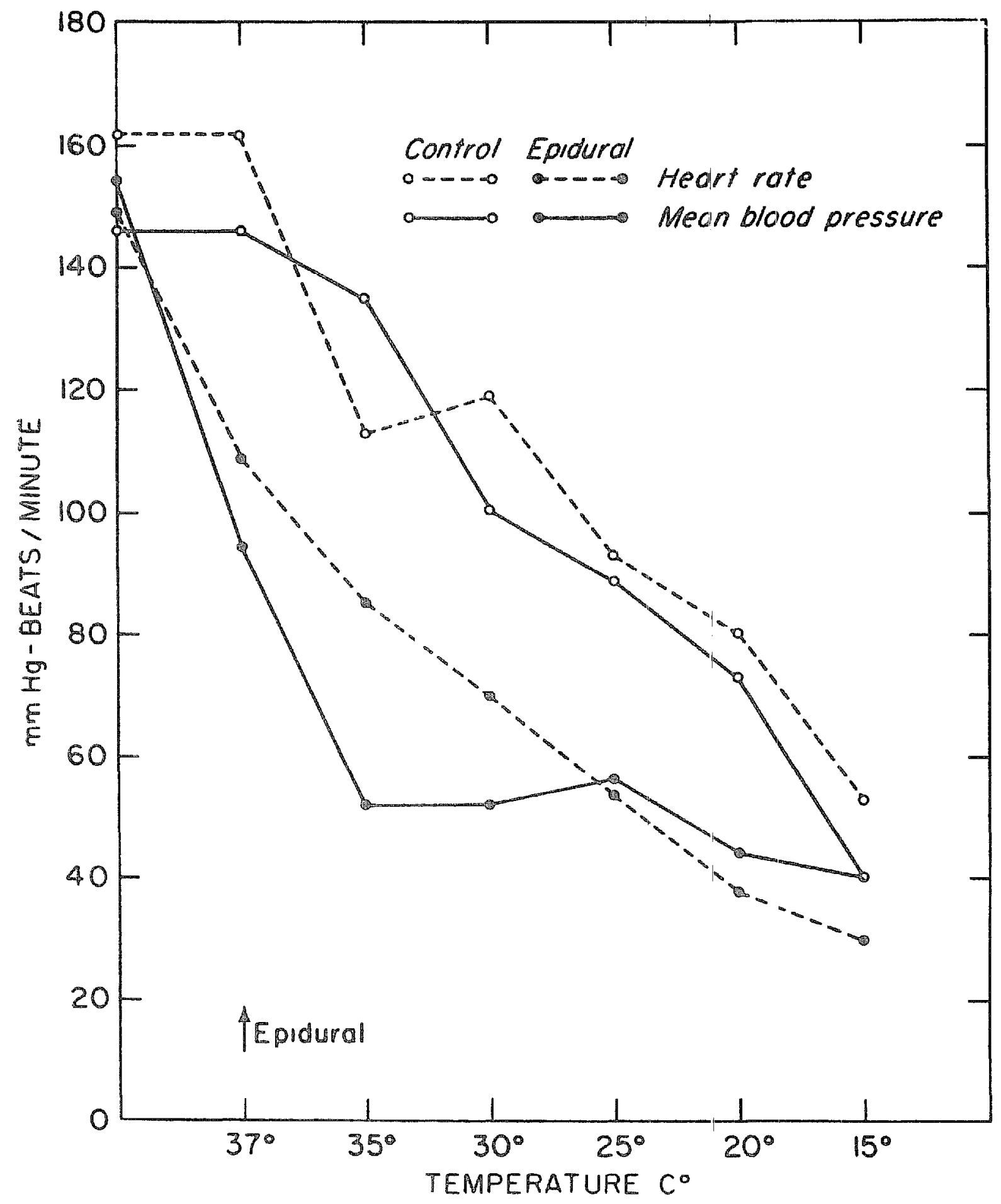

FIgURE 2 Heart rate and blood pressure changes as a function of temperature

Sympathenc block would be expected to protect against the endogenous release of catecholammes but not against their administration

Two principal causes of hypothermic ventricular fibrillation may be considered those initiated by external stimuli, and those occurring spontaneously The former, or induced, may originate in a surgical manoeuvie, an electrical stimulation, or a reflex mechanism and is ieflected in the ventricular fibrillatory threshold The latter, or spontaneous, may originate from a metabolic change ${ }^{10}$ and can be studied through ventricular diastolic threshold determinations Both causes imply modifications in cardiac excitability

The ventricular diastolic threshold (VDT) and the fibrillatory threshold (FT) are affected differently by hypothermia The former (VDT) was unchanged or mcreased at temperatures over $20^{\circ} \mathrm{C}$ and decreased below this temperature, while the latter $(\mathbb{F} T)$ decreases with decreasing temperature 
Szekeres, ${ }^{11}$ comparing thresholds and arrhythmias in the heart in situ with those in the heart-lung preparation, also suggested the existence of two kinds of hypothermic ventricular arrhythmias Hypothermic dogs under epidural anaesthesia behave simularly to heart-lung preparations The VDT: seems to be related to the spontaneous hypothermic ventricular fibrillation and the $F T$ to the induced hypothermic ventricular fibrillation

The diastolic threshold reflects a cellular property Cardiac arrhythmias originating from its modifications may be considered as of spontaneous occurrence This threshold was higher in moderate hypothermia (over $25^{\circ} \mathrm{C}$ ), and agrees with previous observations in which the incidence of hypothermic spontaneous cardiac arrhythmias was decreased, ${ }^{12,13}$ or even disappeared after its induction ${ }^{14}$

The fibrillatory threshold is the myocardial response to a potent artificial stımulus applied towards the end of refractoriness-the vulnerable period ${ }^{7}$ In normothermia this threshold is high (10-20 mamp) and the vulnerable period is short (5-40 msec) In hypothermia this period becomes longer and simultaneously the threshold falls to diastolic levels explaining the ease of induced hypothermic ventricular fibrillation ${ }^{11}$

The coexistence of a lower fibrillatory threshold, a longer relative refractory period, and an ectopic focus as a triggering point, sets the stage for the higher incidence of hypothermic-induced ventricular fibrillation These ectopic foci have been explained by various mechanisms such as uneven cooling of the myocardium, ${ }^{15}$ uneven oxygenation, cold stress, anoxia, or hypercarbia Shumway ${ }^{16}$ reported the existence of particular areas of the myocardium in which the ventricular diastolic threshold was lower under special circumstances Epidural anaesthesia protects against ventricular fibrillation subsequent to cold stress or hypercarbia, by preventıng a reflex sympathetic stimulation

Lower metabolism implies disequilibrium of the intracellular/extracellular relationship of electrolytes, which may account for the higher incidence of spontaneous ventricular fibrillation under $20^{\circ} \mathrm{C}$ Quinidine is supposed to protect at this level Probably epidural anaesthesia provides no protection against this type of ventricular fibrillation

The total refractory period was increased, percentage wise, un the control group, whlle practically no change was found in the epidural group In absolute values, the total refractory period increased with the decrease in temperature in both groups Covino ${ }^{17}$ stressed the importance of the ratio speed of conduction in the myocardium/ventricular refractoriness (QRS/TRP) In our study, the epidural group had a proportional increase in refractoriness and QRS duration and the same proportional decrease in heart rate for any given temperature. In the control group, the changes were unpredictable This harmony in the epidural group seems to be a manifestation of the protective mechanism reported by Covino

\section{SUMMATRY}

The effect of total sympathetic block by epidural anaesthesia was studied during profound hypothermia It protected against the incidence of ventricular 
fibrillation over $20^{\circ} \mathrm{C}$ This protection seemed to be mediated through a steady equilibrium of the heart rate, duration of QRS, and the length of refractormess (TRP) The ventricular fibrillatory threshold became lower and equal to the ventricular diastolic threshold in the animals that fibrillated This threshold (VDT) had wide changes in the control group and decreased sharply below $25^{\circ} \mathrm{C}$ in the experiments in which ventricular fibillation occurred at higher temperatures However, ventricular diastolic threshold alone does not explain the piotection obtained from sympathetic block Sympathetıc block protected against reflex factors in induced ventricular fibrillation Total epidural anaesthesia during hypothermia produced marked arterial hypotension

\section{RÉSUMÉ}

Nous avons étudié l'effet du blocage sympathique total durant l'hypothermie profonde Il a protégé contre l'incidence de fibrillation ventricularre au-dessus de $20^{\circ} \mathrm{C}$ Cette protection semblat être obtenue par un équilibre stable de la vitesse du cceur, d'après le complexe QRS, et par la durée de la réfraction (T R P ) Chez les anımaux qui faisarent de la fibrillation, le seull de la fibrillation ventricularre s'abaissait et devenait égal au seurl cliastolıque ventricularre $\mathrm{Ce}$ seull ( $V \mathrm{DT}$ ) variait beaucoup pour le groupe de contrôle et s'abaissait subıtement au-dessous de $25^{\circ} \mathrm{C}$, lors des expérıences où la fibrillation ventriculaure se produisait à des températures plus élevées Cependant, le seull diastolıque ventricularre seul n'explique pas la protection obtenue par le blocage sympathique Le blocage sympathique protégeait contre les réflexes dans les cas de fibrillation ventriculaire provoquée L'anesthésie épıdurale totale durant l'hypothermie a produit une hypotension an térielle importante

\section{REFERENCES}

1 Hegnauer, A H Lethal Hypothermic Temperatures fol Dog and Man Ann NY Acad Sc1 80316 (1959)

2 Shumacker, $\mathrm{H}$ B, Riberi, A, Boone, $\mathbb{R} \mathbb{D}$, \& $\mathbb{K}$ AjIKuil, $\mathbb{H}$ Ventricular Fibrillation in the Hypothermic State IV The Role of Extrinsic Cardiac Innervation Ann Surg 143223 (1956)

3 Swan, H In Discussion J Thor Cardiovase Surg 38 e38 (1959)

4 Galindo, A, Sprouse, J H Aubry, U, \& Baldwin, $M$ Anesthesia and Ventricular Fibrillation in Deep Hypothermia Proc First European Congr Anesthesiology, p 140 Vienna (1962)

5 Galindo, A \& Sprouse, J H The Effect of Anesthesia on Cardiac Excitability Produced by Single Pulse Electrical Stimulation An Experumental Study Anesth \& Analg 41659 (1962)

6 Galindo, A \& Baldwin, M Profound Hypothermia and Ventricular Fibrillation during Neurosurgery Ann Surg 15630 (1962)

7 Wiggers, $\mathbb{C}$ J \& Wegria, $\mathbb{R}$ Ventricular Fibrillation due to Single, Localized Induiction and Condenser Shocks Applied during the Vulnerable Phase of Ventricular Systole Am J Physiol 128500 (1940)

8 GoldDERG, L I \& SCHMIDT, K $\mathbb{F}$ Effect of Total Epidural Sympathetic Block on Cardiac Arrhythmias Developing dunng Hypothermia Fed Proc 15429 (1956)

9 IstaEL, J S, Dobrin, A G, \& RoBidoux, H J, Jn The Effect of Sympathetic Blockade of Hyperventulation on Epinephrine-Induced Cardiac Arrhythmias during Anaesthesia with Halothane and Methoxyflurane Canad Anaesth Soc J 9125 (1962)

10 Drleze, J Possible Reasons for Drop of Resting Potential of Mammalian Heart Preparations during Hypothermsa Circulat Res 8553 (1960) 
11 Szekeres, L, Meres, I, \& PAPp, J Mechanism of Increased Susceptibility to Fibrillation of the Hypothermic Mammalian Heart in situ Brit J Pharmacol 17: 167 (1961)

12 Beaulnes, A \& DAY, M Effect of Temperatule on Arrhythmia in Isolated Rabbit Atria J Physiol (Lond) 13786 (1957)

13 Goodfond, $\mathrm{P} J$ Metabolic Factors and Ventricular Fibrillation Brit J Pharmacol 13 144 (1958)

14 Somervmle, W The Effect of Hypothermia on Atral Fibrillation and Other Arrhythmias Brit Heart J 22515 (1960)

15 Sealy, W C, Young, W G, Lessage, A M, \& Brown, I W Observations on Heart Action during Hypothermia Induced and Controlled by a Pump Oxygenator Ann Surg 153797 (1961)

16 Shumway, $\mathbb{N} \mathbb{E}$, Jorinson, J A, \& STISH, $\mathbb{R} \mid \int$ The Study of Ventricular Fibrilation by Threshold Determinations J Thor Cardiovasc Surg 34643 (1957)

17 Covino, B G \& D'Amato, H E Mechanism of Ventricular Fibrillation in Hypothermia Circulat Res 10148 (1962) 